\title{
An Eclectic Approach to Teaching the English Tense System to Arabic-Speaking Learners of English: A Pilot Study
}

\author{
Thana Hmidani
}

Near East University

\begin{abstract}
The proper use of tenses is one problem facing Arabic-speaking learners of English when they are taught them and their uses. One of the reasons is the traditional method through which students were taught grammar. The aim of the study is to implement an eclectic approach for teaching the English tenses to Arabic-speaking learners of English.
\end{abstract}

Keywords: Eclectic, approach, teaching, english, tense, system, arabic-speaking, learners, pilot study

\section{Introduction}

Methods: This experimental study took place at CON-A. The subjects are Saudi female freshman nursing students enrolled in an intensive English course. The researcher has developed an eclectic approach to teaching the English Tenses. She implemented her method on the study group, whereas the control group was taught by another instructor. Both instructors are Ph. D holders.

A demographic sheet was designed for the inclusion and exclusion criteria. A pre-test, mid-test and post-test were administered to both groups at three points in time: beginning of the semester, half way through and at the end. They consist of 60 questions equally divided into language awareness tasks, reading and writing skills and vocabulary. The tests covered the course content, were graded by an external examiner. The results were compared with the scores in the pretest and with one another.

Simple random sampling technique was used to select the sample out of 150 students divided into five sections. Descriptive statistics and ANOVA were used to analyze the data.

\section{The Experiment}

The approach is a selection of aspects of different methods combined together in such a way that the resulting activities are compatible, reinforce each other and result in a higher level of linguistic competence. It consists of four main phases: the Reception and Assimilation phase for initiating the students to the new structures, the Accommodation phase covers the intensive practice provided in the book and uses translation, followed by 'Consciousness-raising' tasks and dictogloss. The Production phase sensitizes the students to actual language use and the Self-Assessment phase is an ongoing process throughout the learning process.

\section{Results:}

Using repeated measure ANOVA, the results indicated statistical significant differences between the two groups over time regarding Language awareness $(F(1,18)=6.02, P=.03)$ and Reading and Writing skills $(F(1,18)=7.30, P=.02)$; except for Vocabulary $(F(1,18)=2.28, P=.15)$

\section{Conclusion}

The highest effect of the approach appeared in the language awareness. This was expected because the students are already taking reading and writing courses whereas language awareness is the goal of the grammar course. Larger sample is needed to verify the effectiveness of the approach. 